\author{
UNITED STATES \\ DEPARTMENT OF THE INTERIOR \\ GEOLOGICAL SURVEY
}

\begin{abstract}
AVAILABILITY OF FORAMINIFERA AND PALYNOMORPH REPORTS FROM SHOTHOLE SAMPLES OF

NATIONAL PETROLEUM RESERVE IN ALASKA
\end{abstract}

By

H. A. Gibson and Arthur L. Bowsher

OPEN-FILE REPORT NO. $81-1340$

This report is preliminary and has not been reviewed for conformity with Geological Survey editorial standards and stratigraphic nomenclature. 


\section{Availability of Foraminifera and Palynomorph Reports \\ from Shothole Samples of \\ National Petroleum Reserve in Alaska}

Shothole samples were collected from seismic lines within the boundaries of the National Petroleum Reserve in Alaska. Geophysical Services, Inc., subcontracted by Husky Oil NPR Operations, Inc., surveyed the seismic lines and collected bottom-hole samples at depths of 90 and 105 feet. However, the sample selection for this study was restricted to eight seismic lines and the availability of samples for those selected lines which was established to be an interval between 440 and 880 feet (Figure 1). Rock samples from the eight seismic lines were submitted to Anderson, Warren, and Associates for palynomorph and foraminifer processing.

Table 1 indicates the line numbers, seismic point (shothole sample) interval, and the number of samples processed for that interval.

\section{TABLE 1}

Line No.

$$
\begin{aligned}
& 29 \\
& 37 \\
& 37 x \\
& 45 \\
& 45 x \\
& 46 \\
& 51 \\
& 51 x
\end{aligned}
$$

\section{Sample Preparation}

A total of 1,365 shothole samples from selected seismic lines were processed using standard laboratory techniques. Samples were washed over 20 and 200 mesh screens and boiled in a Quaternary-0 solution. Washed samples were then picked and mounted on slides for examination.

Foraminifera and Palynomorph Reports

Anderson, Warren, and Associates prepared foraminifera and palynomorph reports for the shothole samples. The reports include a detailed listing of genera, a brief lithologic description, and an age and environment determination.

\section{Report Request}

Requests for copies of the reports should be addressed to:

National Geophysical and Solar-Terrestrial Data Center (D-621) NOAA/EDIS/NGSDC

Boulder, Colorado 80303

Telephone: (303) 499-1000 (ext. 6338) 


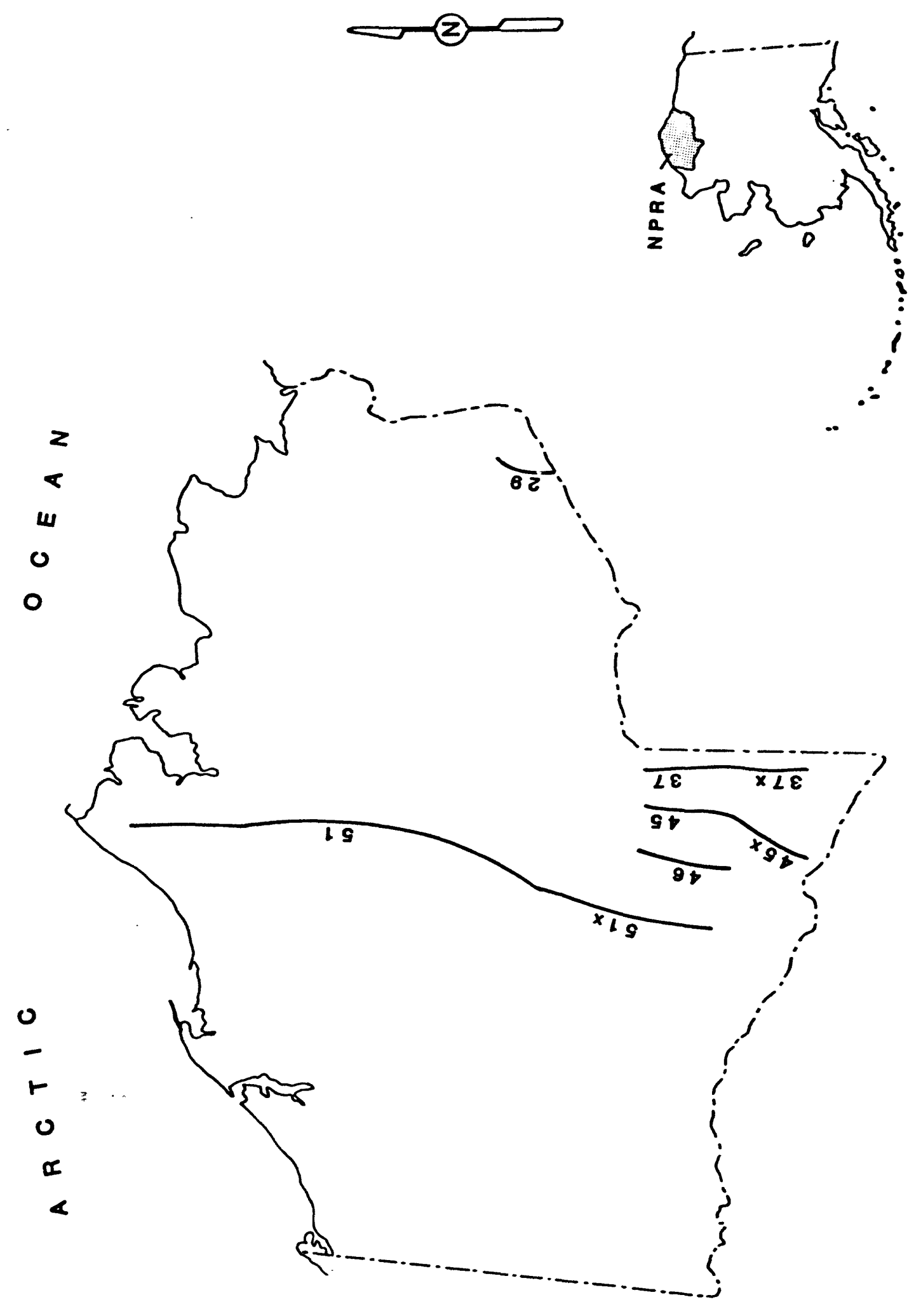

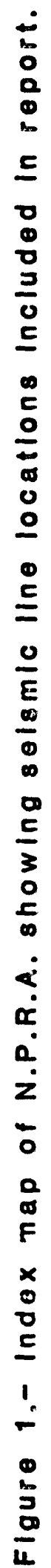




\section{On-site Examination}

Washed residues with picked slides are available for examination at:

U.S. Geological Survey, MS 87

Office of National Petroleum Reserve in Alaska

Casa Mills Building, Room 239

200 Middlefield Road

Menlo Park, California 94025

Microscope not available. 